\title{
INTENTIONS FOR PROFESSIONAL REALIZATION FOR MIDWIFE INTERNS FROM THE MEDICAL UNIVERSITY OF VARNA
}

\author{
Valya Dimitrova \\ Department of Health Care, Faculty of Public Health, Medical University of Varna
}

\begin{abstract}
AIM: The aim of this paper is to observe the motivation when choosing the Midwife program and the intention for professional development of midwife interns at the Medical University of Varna.
\end{abstract}

MATERIALS AND METHODS: The methods used were:

- Sociological method - a survey, involving midwife interns at the Medical University of Varna, graduated in 2012, 2013, 2014 and 2015 (75 individuals);

- Documentary method - analysis of appropriate literature and academic documentation.

RESULTS AND DISCUSSION: The majority of the respondents had enrolled in the Midwife program by their own choice. Midwife interns consider that they have gained the theoretical and practical knowledge needed for a solid start in the profession. While in training at the Medical University of Varna, the students have determined that education and self-development in the field are the key for a successful professional realization. Students show the intention to participate in various forms of ongoing and continuous trainings, which is a serious commitment to public health and the profession itself.

CONCLUSIONS: The university degree is not just a goal for young people, but also a well-determined choice and self-commitment to society. Midwives are specialists in their own field of expertise and in their range of activities when providing care for female reproductive health.

Keywords: midwife, motivation, intentions, professional realization

Address for correspondence:

Valya Dimitrova

Faculty of Public Health

Medical University of Varna

55 Marin Drinov St

e-mail:valadim@abv.bg

\section{INTRODUCTION}

Midwives as medical professionals have undergone a process of reevaluation and development in recent years. Higher importance has been placed on pursuing goals related to increasing knowledge, skills and competences in midwives, establishing their selfesteem and confidence, as well as acknowledgement and delegation of traditional functions conducted by midwives. Consulting women in relation to their reproductive health care is the field of the midwife's expertise, which can be further applied and placed in a 
strictly scientific field, based on the knowledge, skills and professionalism of the obstetrics community.

\section{RESULTS AND DISCUSSION}

The motivation when choosing this program has a key importance both for gaining professional knowledge and skills, and for eventual future professional realization. Interesting fact is how midwife interns have become a part of the Midwife program, while applying for Medical University of Varna (Fig. 1).

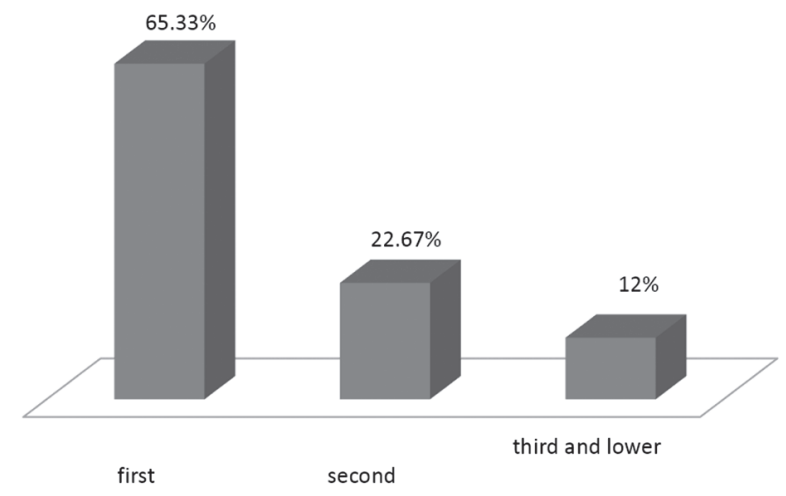

Figure 1. Motivation when choosing the Midwife program

The analysis of the results clearly shows that the majority of the respondents are studying in the field based on their $1^{\text {st }}$ choice when they were applying for university (65.33\%), which is sufficient evidence for the desire for gaining specific knowledge and skills. About a third (1/3) of the respondents have made it based on their second choice (22.67\%), and it was listed at a 3 rd or lower place for only $12 \%$, which can be interpreted as students in need of increasing their personal motivation or students who will potentially drop out during the course of study. It is rather important to point out that in each consecutive class, the proportion of students admitted to the University by their second or lower choice is decreasing, which can be explained by their better understanding and information, the better organization of the student campaigns, Open Doors days, etc.

Acquiring basic professional knowledge and skills impacts directly the prospective realization of the future midwives, building their professional outlook and their confidence as specialists and their attitude towards practicing the profession. The opinion of the students regarding the acquired basic knowl- edge and skills, professional competency and successful mastering of the profession during the course of study was inquired (Fig. 2).
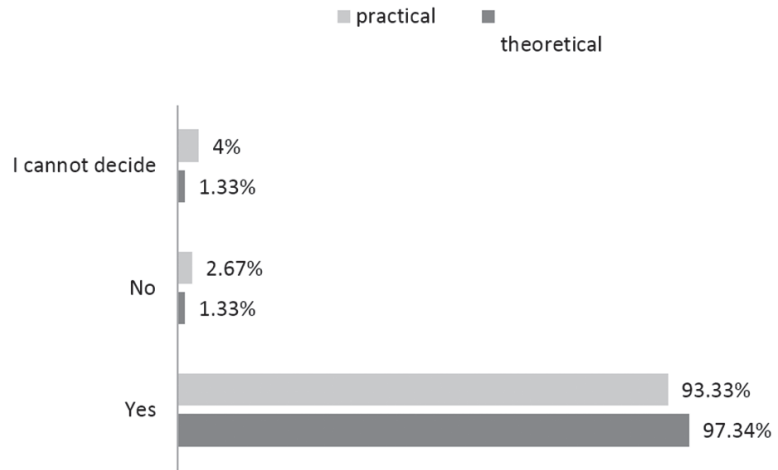

Figure 2. Gained theoretical and practical knowledge for successful acquaintance with the profession

Almost every respondent shares that they have gained sufficient theoretical (97.34\%) and practical (93.33\%) knowledge, needed for a successful start in the profession. The students' replies can be defined as an excellent testimonial for the organization and conduction of the theoretical and practical training in the Midwife program at the Medical University of Varna.

Further proof of that is the presented intention for subsequent professional realization of the the majority of the inquired students (Fig. 3).

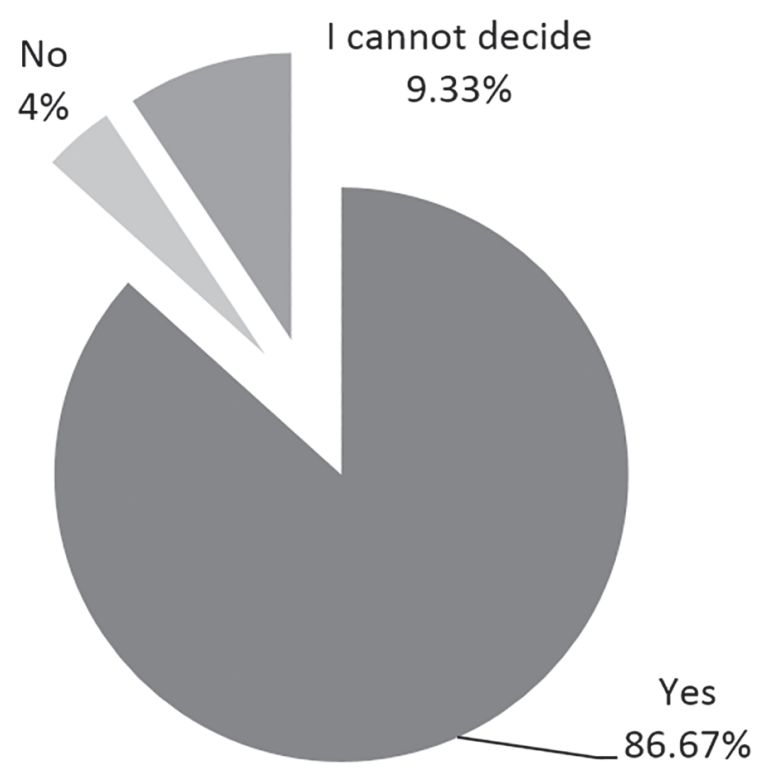

Figure 3. Intentions of practicing the midwife profession 
The majority of the inquired present firm intentions towards their professional realization as midwives (86.67\%). The responses can be interpreted as a fact showing that the University degree is not just a self-accomplishment target for the students, but also a well understood public and social engagement, which they are willing to take.

After the year 2007, the education for midwives in Bulgaria has been synced with the educational programs in all other EU countries, which allows the free movement of professionals. A high number of countries worldwide have acknowledged the education in Bulgaria and value the professional qualification of our health care specialists. We have surveyed the intentions of the just-graduated midwives for realization abroad (Fig. 4).

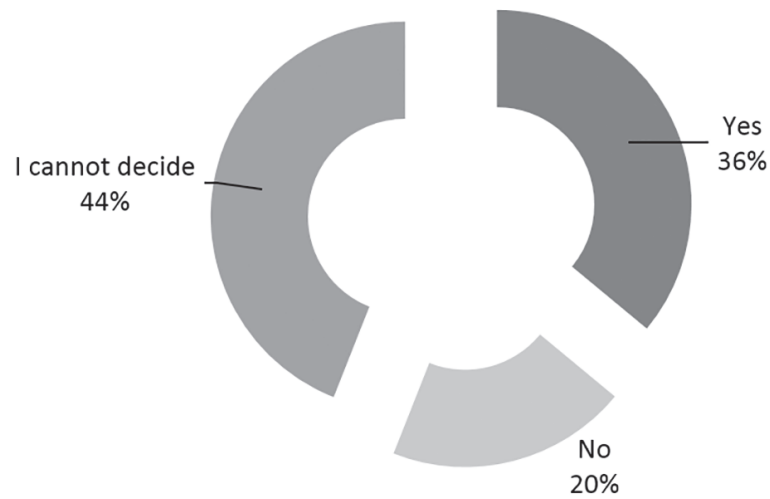

Figure 4. Intention for realization abroad

Slightly more than $1 / 3$ of the inquired state firmly their intention of working abroad (36\%), and almost $1 / 2$ of the respondents do not rule out such possibility (44\%). Worrying is the fact that the proportion of the midwives, who do not have the intention to practice the profession outside Bulgaria is so low (20\%). The response testifies that we have a strong need of finding mechanisms and we need to take emergency measures in order to hold these professionals here in Bulgaria.

The intentions of professional realization are relatively close to the goals of self-development and improvement. This is due to the rapid development of medicine as a science and the constantly changing needs of the ones looking for obstetrics health care services. It was rather important and interesting for us to find out how important personal development is for the students (Fig. 5).

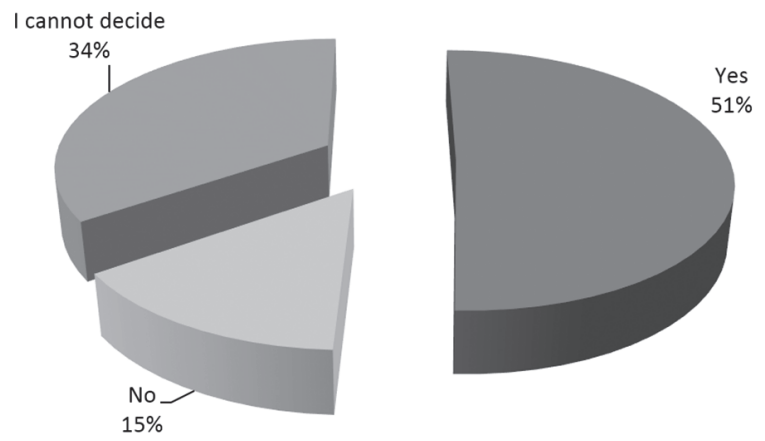

Figure 5. Intentions for continuing the education to the next degree

Around $1 / 2$ of the inquired students have stated their intention in achieving a Master's degree (50.67\%), and a bit more than $1 / 3$ expressed hesitation (34.66\%). The proportion of the students, who do not really find it a necessity to continue their education is rather small - $14.67 \%$. The respondents' opinion is clearly stating that they have realized, during their course of study, that the education and their improvement in the profession can give them more options to choose from, can help them practice the profession successfully and have a chance for better professional realization. The reply can also be interpreted as a strong will of intention to study and gain knowledge throughout the whole career path, which can be considered a guaranteed successful practicing of the profession.

The midwife interns' intentions and attitude towards continuous training throughout their career path are shown in the response to the questions about their plans to participate in various forms of post-graduate and continuous education (Fig. 6).

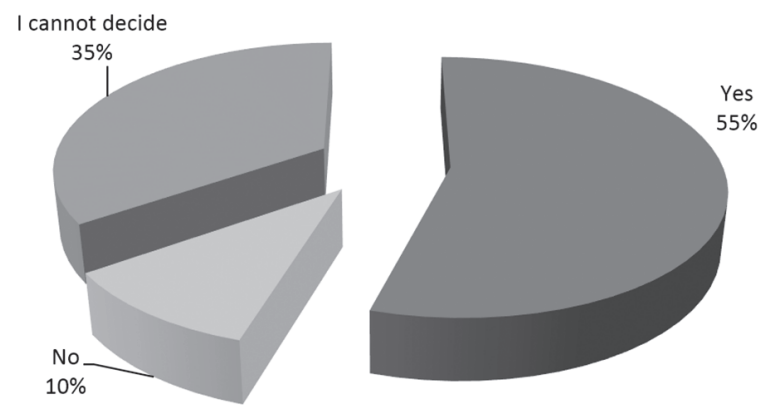

Figure 6. Intentions of participation in various continuous educational forms 
More than a half of the inquired state firmly their intentions to continue their professional development and growth (54.67\%), and about $1 / 3$ show hesitation but are not willing to rule it out as an opportunity (34.67\%). The opinion of the students shows how seriously they are taking their future professional responsibilities in the public health care sphere.

The problems which practicing midwives encounter nowadays are having direct impact on the decision making process while choosing both the Midwife program and the profession. During the clinical practice, they are studying in a real-life work environment and become part of the daily, routine problems, which the practicing midwives are faced with, which is why we wanted their opinion. The majority of the inquired interns pointed the underpayment issue as the main problem (94.76\%). A bit more than $1 / 2$ of them think, that the lower number of staff also has a negative effect (38.76\%) as well as the various and at the same time too different duties of the midwives (20\%). The opinion of the inquired shows that the main problems are both financial and organizational, which calls for a redesign of the organizational structure and paying practicing midwives adequately. There is a need of establishing alternative structures for obstetrics health care, proper evaluation obstetrics activities, etc. This is a small part of the activities, which can lead to a more flexible definition of the accurate calculation for payment for professions in the field of obstetrics (Fig. 7).

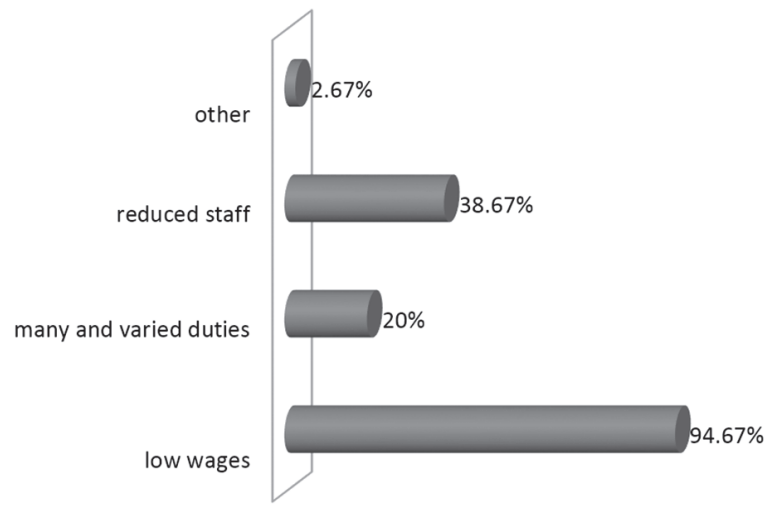

Figure 7. Problems for practicing midwives

It was rather important for us to see how midwife interns understand the opportunity of profes- sional autonomy. We asked them whether they consider contemporary midwives capable of conducting autonomous functions when providing obstetrics health care services and consulting pregnant and post-partum women. The response was clear - almost all of the respondents was confident that midwives have the potential to provide autonomous heath care services in women consultations (86.66\%) (Fig. 8).

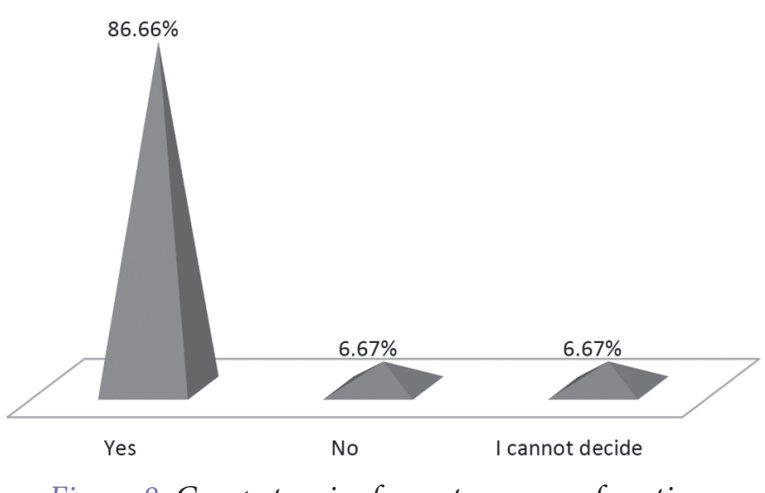

Figure 8. Competencies for autonomous functions

The proportion of those hesitating or totally declining such opportunity is considered negligible $(6.67 \%)$. The opinion of the inquired respondents clearly outlines that the midwives are professionals with their own place and field of expertise in conducting reproductive health care services.

The results allow us to make the following conclusions:

1. The majority of the midwives from the Medical University of Varna have enrolled in the program as their 1st choice, which is a good prerequisite to have sufficient motivation while gaining specific knowledge and skills during their course of study (65.33\%).

2. Midwife interns from the Medical University of Varna state that they have gained their theoretical (97.34\%) and practical (93.33\%) knowledge during their education, which is what is needed for a successful career start in the profession.

3. During their course of study at the Medical University of Varna, the students have realized that the training and the self-improvement have a key role in the future professional realization (50.67\%). 
4. The problems for practicing midwives are mainly related to financial $(94.67 \%)$ and organizational (38.67\%) issues, which call for rethinking the organizational and financial side in the field of obstetrics.

5. Students show readiness to participate in different forms of continuous education (54.67\%), which shows the potential for strong engagement in the sphere of public health care where they will practice their profession.

\section{CONCLUSION}

The university degree is not just a self-accomplishment target for the students but also a well understood public and social engagement, to which they are willing to commit. Midwives are professionals with their own place and field of expertise, which consists of providing reproductive health care services.

\section{REFERENCES}

1. Alexandrova M, Trendafilova P. Nurse Education in the context of never ending education on the work place. Proceedings. Trakia Journal of Sciences. 2008 ; 6(2).

2. Bacheva M. Reform of the medical education and medical help. Heath Economics and Management. 2013; 4(50).

3. Borisova S. Introduction of new technologies when providing health care services. National Forum for Specialists in Health Care "Encounters among the health care professionals in process of Euro-integration". Proceedings and resumes, Pomorie. 2008.

4. Borisova S. International experience in standardizing the nurse's activity. National Forum for Health Care specialists "Encounters among the health care professionals in process of Euro-integration". Proceedings resumes, Pomorie. 2008.

5. Borisova S. Necessity of additional education for applying innovations in nurse's practice. Innovations in Education, Shumen. 2010.

6. Borisova S. University education for nurses as an opportunity for introducing innovative practices. Dis, Sofia. 2010.

7. Toncheva S. There is a need of a new organizational structure and applying new European models for nurse praciticing in PZP. Hygiene and healthcare. 2001; 45.
8. Toncheva S, Zagorchev P, Tsvetkova T, Borisova S. Handbook of nurses in outpatient care. Sofia: Filvest; 2001.

9. Toncheva S. Educational aspects of the contemporary nursing in Bulgaria. Regional forum of the heath care specialists. Proceedings and abstracts, Shumen. 2009.

10. Toncheva $S$, Chepisheva M. Building of a nursing serving structure in MBAL. Health Care. 2011; 4.

11. Toncheva $S$, Chepisheva M. Nursing serving structure - innovative approach for conducting continuous health care. IX National Forum for the health care specialists. Proceedings and abstracts, Shumen,. 2011.

12. Toncheva S, Muglova M. Midwives' attitude and readiness to conduct autonomous activity. Health Care. 2012; 1.

13. Casey M. Interorganisational partnership arrangements: a new model for nursing and midwifery education. Nurse educ. today. 2011: 31(3).

14. Price B. Key principles in assessing students practice based learning. Nurs stand. 2012; 26 (49). 